\title{
Numerical simulation and optimization of hot stamping and quenching processes of automobile anticollision beam
}

\author{
Zezhong Chen ${ }^{1, a}, \mathrm{Xi} \mathrm{Su}^{2, \mathrm{~b}}$ and Xueyuan $\mathrm{Li}^{3, \mathrm{c}}$ \\ 1,2,3School of Materials Science and Engineering, University of Shanghai for Science and \\ Technology, Shanghai 200093, China \\ azzhchen@usst.edu.cn, b330984149@qq.com, cqianlansejiyi@qq.com
}

\begin{abstract}
Keywords: Numerical Simulation; Optimization; Hot Stamping; Quenching; Anticollision Beam Abstract. LS-DYNA and ANSYS software are adopted to simulate hot stamping and quenching processes of M-shaped $1038 \mathrm{~mm}^{*} 1.85 \mathrm{~mm}$ B1500HS automobile anticollision beam. Different stress distribution are obtained among different start temperature as $800{ }^{\circ} \mathrm{C}, 850{ }^{\circ} \mathrm{C}, 900{ }^{\circ} \mathrm{C}, 950{ }^{\circ} \mathrm{C}$ and different stamping velocity as $25 \mathrm{~mm} / \mathrm{s}, 50 \mathrm{~mm} / \mathrm{s}, 75 \mathrm{~mm} / \mathrm{s}$ and $100 \mathrm{~mm} / \mathrm{s}$. The higher the start temperature, the better the metal formability; the higher the temperature at the end of forming, the smaller the flow stress. The faster the stamping velocity, the shorter the cooling time, and the lower the maximum flow stress. After optimization, the difference between the minimum and maximum temperature of forming part decreases from $74^{\circ} \mathrm{C}$ to $47^{\circ} \mathrm{C}$, indicating that the temperature distribution after cooling is more uniformed.
\end{abstract}

\section{Introduction}

Hot stamping technology means the sheet metal is heated above the austenite temperature and insulate for a period of time in order to make materials complete austenitizing, then stamped and quenched in closed water cooling die which causes materials phase changed from austenitic structure to martensitic structure [1], the strength of the final parts is up to $1500 \mathrm{Mpa}$. The processes include two stages: forming and quenching[2].

\section{Numerical simulation}

The M-shaped $1038 \mathrm{~mm}^{*} 1.85 \mathrm{~mm}$ B1500HS automobile anticollision beam is studied (Fig. 1). The hot stamping forming is carried out without blank holder, and cooling water is cycled in cooling runners among the die during stamping and quenching. Radius of cooling runners is less than $5 \mathrm{~mm}$ in order to improve service life of the die.
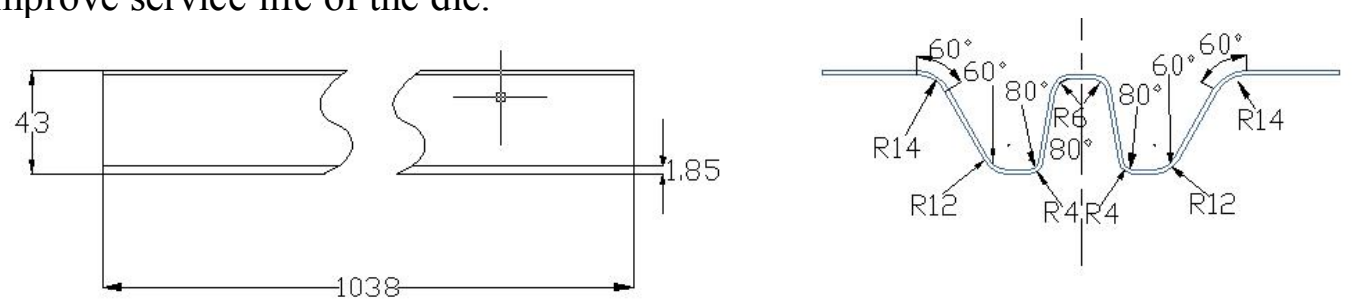

Fig. $1 \mathrm{M}$-shaped $1038 \mathrm{~mm}^{*} 1.85 \mathrm{~mm}$ B1500HS automobile anticollision beam

LS-DYNA software is adopted to simulate the hot stamping and quenching processes (Fig. 2). High temperature characteristics of material should be considered, which means the coefficient of heat conduction, the specific heat and the thermal expansion coefficient of B1500HS are all variables [3]. The forming time is set as $0.2 \sim 1 \mathrm{~s}$. The quenching time is set as $2 \sim 10 \mathrm{~s}$ in view of the heat transmission among punch, die and cooling water, ensuring that the quenching process meets the martensitic formation temperature. 


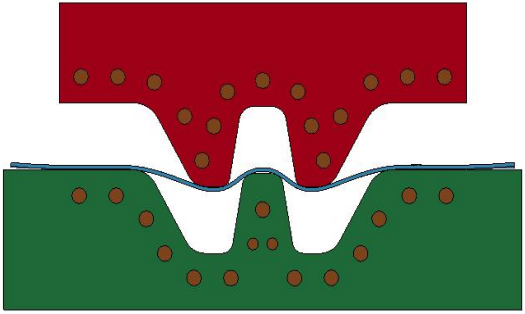

(a) $0.06 \mathrm{~s}$

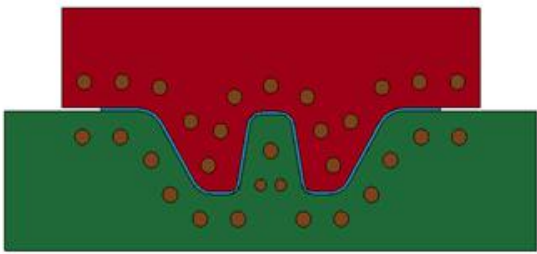

(b) $0.2 \mathrm{~s}$

\section{Analysis}

Fig. 2 Forming process of anticollision beam

When the start temperature of the sheet ranges from $800^{\circ} \mathrm{C}$ to $950^{\circ} \mathrm{C}$, and the velocity of the stamping is set as $100 \mathrm{~mm} / \mathrm{s}$, the distribution of the end temperature and stress is shown in Fig. 3 and 4.

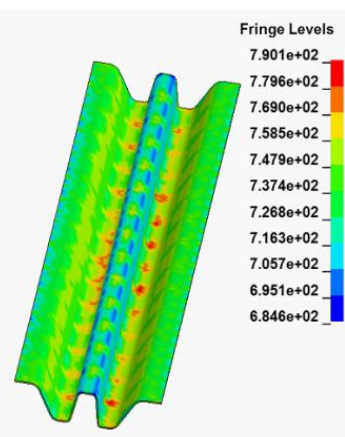

(a) $800^{\circ} \mathrm{C}$

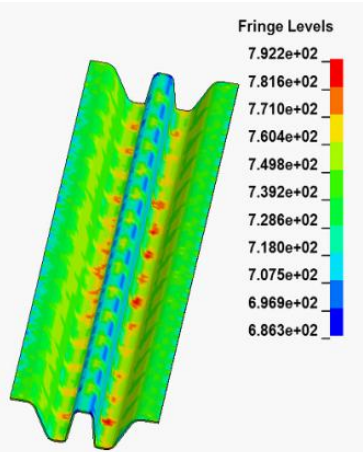

(b) $850^{\circ} \mathrm{C}$

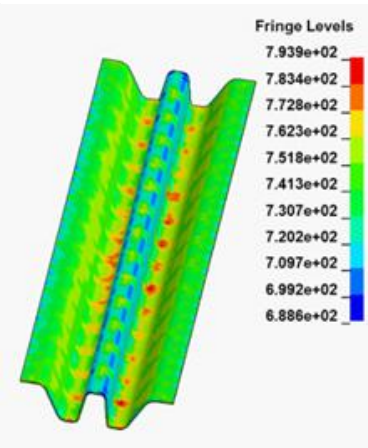

(c) $900^{\circ} \mathrm{C}$

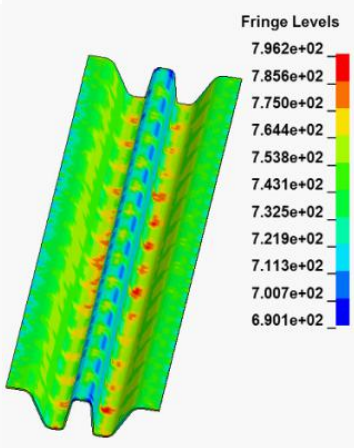

(d) $950^{\circ} \mathrm{C}$

Fig. 3 End temperature distribution of forming parts in different start temperatures

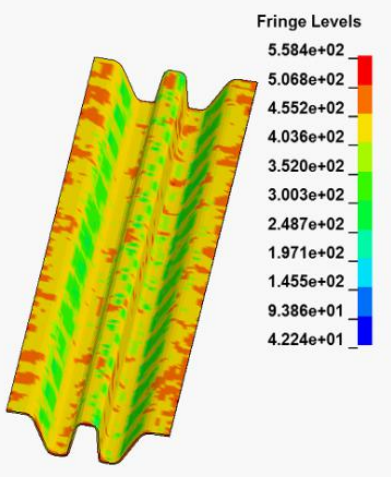

(a) $800^{\circ} \mathrm{C}$

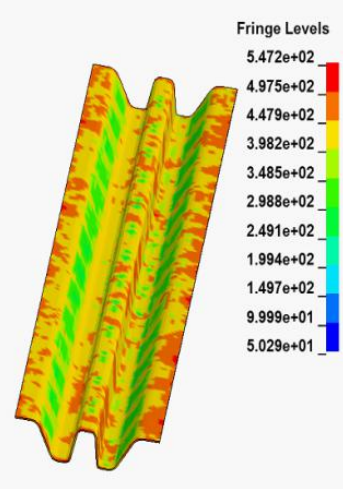

(b) $850^{\circ} \mathrm{C}$

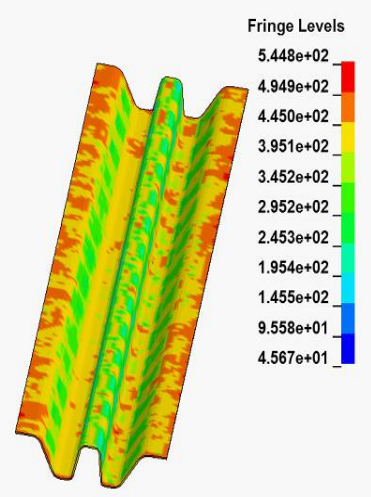

(c) $900^{\circ} \mathrm{C}$

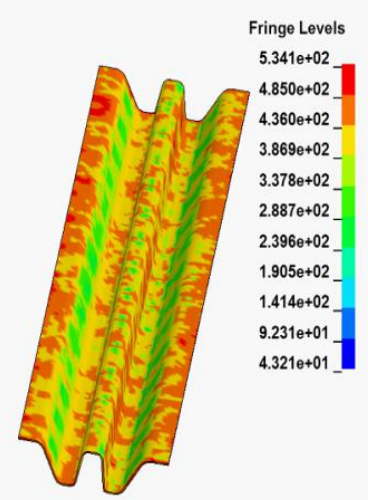

(d) $950^{\circ} \mathrm{C}$

Fig. 4 Stress distribution of the forming parts in different start temperatures

If the start temperature of the sheet is set uniformly as $950{ }^{\circ} \mathrm{C}$, the stamping speed ranges from $25 \mathrm{~mm} / \mathrm{s}$ to $100 \mathrm{~mm} / \mathrm{s}$, the temperature and stress after forming is shown in Fig. 5 and 6 .

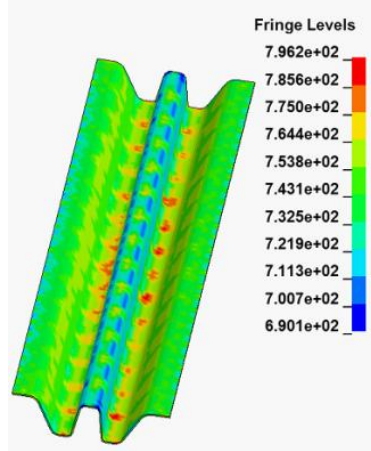

(a) $25 \mathrm{~mm} / \mathrm{s}$

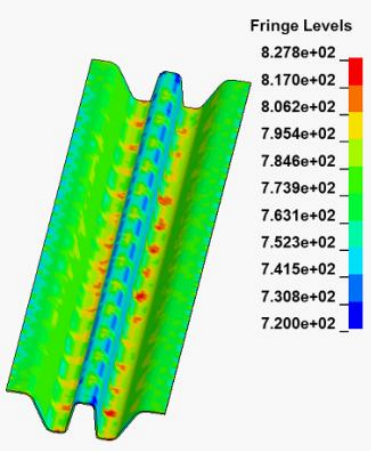

(b) $50 \mathrm{~mm} / \mathrm{s}$

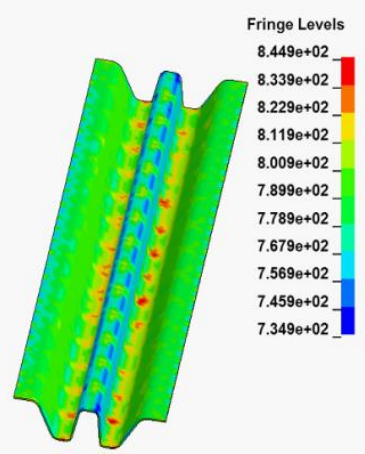

(c) $75 \mathrm{~mm} / \mathrm{s}$

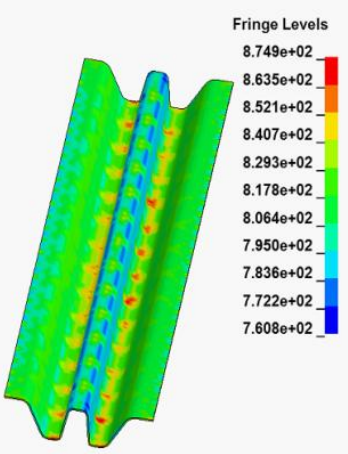

(d) $100 \mathrm{~mm} / \mathrm{s}$

Fig. 5 End temperature distribution of forming parts in different stamping speeds 


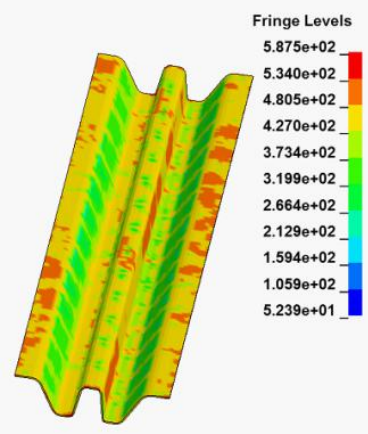

(a) $25 \mathrm{~mm} / \mathrm{s}$

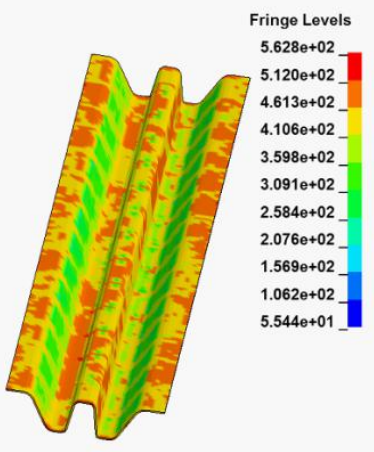

(b) $50 \mathrm{~mm} / \mathrm{s}$

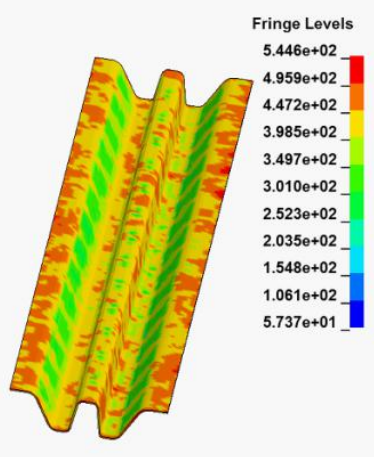

(c) $75 \mathrm{~mm} / \mathrm{s}$

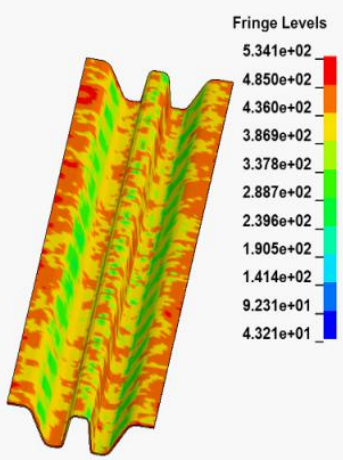

(d) $100 \mathrm{~mm} / \mathrm{s}$

Fig. 6 End stress distribution of forming parts in different stamping speeds

\section{Optimization}

Based on ANSYS software, a 2D simulation model of quenching system is established (Fig. 7). The material parameters are the same as before, and the start temperature of material, die and cooling water are defined as $950{ }^{\circ} \mathrm{C}, 25^{\circ} \mathrm{C}$ and $15^{\circ} \mathrm{C}$. Heat solid element PLANE55 is set for the mesh definition [4].

Transient temperature distributions of hot stamping parts and die after 8s cooling and quenching processes are simulated, as shown in Fig. 7, which shows that the maximum temperature of forming parts reaches up to $242.792^{\circ} \mathrm{C}$ after cooling and quenching, while the minimum temperature value is 168. $706^{\circ} \mathrm{C}$, and the difference between the maximum and minimum temperature is about $74^{\circ} \mathrm{C}$.

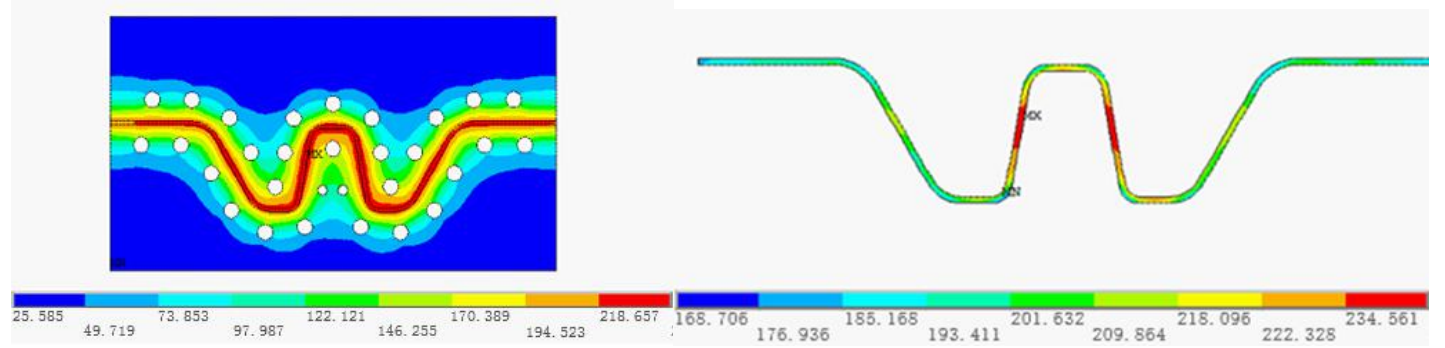

Fig. 7 Temperature distribution of die and forming parts after 8s cooling and quenching The influence factors of die structure to forming parts' cooling and quenching include cooling water runner radius, runners' spacing and the distance between runner and forming surface. In order to optimize cooling and quenching, the vertical and horizontal coordinates of runner center, and the runner radius are selected as variables to be optimized. The objective function is as follows [5]:

$$
F(\varphi)=\mu \sum_{i=1}^{N}\left[\frac{T_{i}(\varphi)}{\bar{T}}-1\right]^{2}+(1-\mu) \bar{T}
$$

Where, $\varphi$ is the variables to be optimized; $\mu$ is the weight coefficient, ${ }^{T}$ is the temperature of every selected node in cross-section; $\bar{T}$ is the average temperature of selected nodes in cross-section; $N$ is the amount of selected nodes in cross-section.

Five groups of variables values after optimization are simulated and showed respectively in Table 1, wherein, $\mathrm{R}$ is runner radius, $\mathrm{a}$ is vertical coordinates of upper die runner center, $\mathrm{b}$ is horizontal coordinates of upper die runner center, $\mathrm{c}$ is vertical coordinates of lower die runner center, $\mathrm{d}$ is horizontal coordinates of lower die runner center. 
Table 1 Variables of runner after optimization $(\mathrm{mm})$

\begin{tabular}{|c|c|c|c|c|c|c|c|c|}
\hline \multirow{2}{*}{$\begin{array}{l}\text { Ordinate of upper } \\
\text { die runner center }\end{array}$} & a1 & $\mathrm{a} 2$ & a3 & $\mathrm{a} 4$ & $\mathrm{a} 5$ & $\mathrm{a} 6$ & a7 & a8 \\
\hline & 144.23 & 144.50 & 136.55 & 119.60 & 102.90 & 119.97 & 136.74 & 142.26 \\
\hline \multirow{2}{*}{$\begin{array}{l}\text { Abscissa of upper } \\
\text { die runner center }\end{array}$} & b1 & $\mathrm{b} 2$ & $\mathrm{b3}$ & b4 & b5 & b6 & $\mathrm{b} 7$ & \\
\hline & 90.59 & 70.78 & 52.55 & 42.43 & 30.26 & 25.87 & 20.31 & \\
\hline \multirow{2}{*}{$\begin{array}{l}\text { Ordinate of lower } \\
\text { die runner center }\end{array}$} & $\mathrm{c} 1$ & $\mathrm{c} 2$ & $\mathrm{c} 3$ & $\mathrm{c} 4$ & $\mathrm{c} 5$ & c6 & $\mathrm{c} 13$ & $\mathrm{c} 14$ \\
\hline & 120.23 & 120.6 & 106.87 & 89.14 & 78.79 & 80.87 & 118.77 & 99.23 \\
\hline \multirow{2}{*}{$\begin{array}{l}\text { Abscissa of lower } \\
\text { die runner center }\end{array}$} & $\mathrm{d} 1$ & $\mathrm{~d} 2$ & $\mathrm{~d} 3$ & $\mathrm{~d} 4$ & $\mathrm{~d} 5$ & $\mathrm{~d} 6$ & & $\mathrm{~d} 14$ \\
\hline & 95.33 & 76.27 & 61.81 & 51.96 & 34.42 & 14.03 & & 6.47 \\
\hline \multirow{2}{*}{$\begin{array}{l}\text { Radius of cooling } \\
\text { runner }\end{array}$} & $\mathrm{R}$ & & & & & & & \\
\hline & 4.84 & & & & & & & \\
\hline
\end{tabular}

The objective function value is 1658 after optimization which reduces by $30 \%$ than the value as 2373 before optimization. After optimization, the maximum temperature of the forming part is only $186.872{ }^{\circ} \mathrm{C}$, which reduces by about $56{ }^{\circ} \mathrm{C}$ than the value before optimization, and the difference between the maximum and minimum decreases from $74^{\circ} \mathrm{C}$ to $47^{\circ} \mathrm{C}$.

\section{Conclusions}

With the use of LS-DYNA and ANSYS software, the hot stamping and quenching processes of M-shaped $1038 \mathrm{~mm}^{*} 1.85 \mathrm{~mm}$ B1500HS automobile anticollision beam is simulated and optimized. Different stress distribution are obtained among different start temperature as $800^{\circ} \mathrm{C}, 850^{\circ} \mathrm{C}, 900^{\circ} \mathrm{C}$, $950^{\circ} \mathrm{C}$ and different stamping velocity as $25 \mathrm{~mm} / \mathrm{s}, 50 \mathrm{~mm} / \mathrm{s}, 75 \mathrm{~mm} / \mathrm{s}$ and $100 \mathrm{~mm} / \mathrm{s}$. The higher the start temperature, the better the metal formability; the higher the temperature at the end of forming, the smaller the flow stress. The faster the stamping velocity, the shorter the cooling time, and the lower the maximum flow stress.

After optimization, the difference between the minimum and maximum temperature of forming part decreases from $74^{\circ} \mathrm{C}$ to $47^{\circ} \mathrm{C}$, indicating that the temperature distribution after cooling is more uniformed.

\section{References}

[1] Abdulhay, B., Bourouga, B., Dessain, C. Experimental and theoretical study of thermal aspects of the hot stamping process. Applied Thermal Engineering 31, 674-685. (2010)

[2] Merklein, M., Lechler, J., Stoehr, T. Investigations on the thermal behavior of ultra high strength boron manganese steels within hot stamping. International Journal of Material Forming 2, 259-262. (2009)

[3] Bosetti, P., Bruschi, S., Stoehr, T. Interlaboratory comparison for heat transfer cofficient identification in hot stamping of high strength steels. International Journal of Material Forming 3, 817-820. (2010)

[4] Caron, E., Daun, K.J., Wells, M.A. Experimental characterization of heat transfer coefficients during hot forming die quenching of boron Steel. Metallurgical and Materials Transactions B 44, 332-343. (2013)

[5] CHOI, H.S., KIM, B.M., NAM, K.J. Development of hot stamped center pillar using form die with channel type indirect blank holder. International Journal of Automatic Technology 12, 887-894. (2011) 